\title{
Literature Review of the Implementation Evaluation on Land Use Planning
}

\author{
Guo-hua LIU \\ China University of Geosciences, Wuhan 430074, China \\ e-mail: 9257470@qq.com
}

\begin{abstract}
With the fast development of social economy, the contradictions between social development and land use are becoming increasingly serious. In order to ease the contradiction between human and land, and promote the balanced development between social economy and resource environment, there should be a higher request for land use planning. As the leading of land management career in China, the integrated land use planning has an indispensable position in configuration and management of territorial resources, and the vitality of land use planning lies in implementation, evaluating the implementation of integrated land use planning is the effective mean to test the test the viability of planning. At the same time, take a reasonable assessment for the last round of the implementation of land use planning is beneficial to promoting the revision, implement and the development of the new round of land use planning into the virtuous track, ensure the planning to provide a better service to social and economic development. Over the years, scholars of international and domestic have been researching the implementation evaluation on land use planning, accumulated plenty of experiences and provided a variety of document literature. Based on reading a large amount of literature, this article generalized and summarized the previous studies of the implementation evaluation on land use planning, the research focuses on the course of the implementation evaluation on land use planning. The stage of preparation of the implementation evaluation on land use planning in China (the mid of 1980s), the stage of constructing evaluation indicator system and perfecting evaluation methodology under the guidance of relevant policies (formed from mid 1990s), the stage of multi-directions in extension of research viewpoints (since 2000). This article concluded and summarized the assessment indicator system, weight, method of assessment, assessment cases and hot research of integrated land use planning, proposed that take an in-depth evaluation on PLF benefits in the implementation evaluation on land use planning in future, established an environmental impact evaluation system of integrated land use planning which based on landscape ecology.
\end{abstract}

Keywords-component; evaluation; land use planning; evaluation indicator; weight; evaluation method

\section{INTRODUCTION}

The integrated land use planning is research and analyze the land use, enable land use to meet the development needs for the future, coordinate the relation between human and land, and achieve the sustainable development of resources within a certain space-time. Nowadays, with the fast development of economy in China, the integrated land use planning has become the basic standard of different levels of land use, the reasonable land use could promote the development of economy, society, and ecology, and the implementation evaluation on land use planning is an effective mean to test the vitality of land use planning. In addition, the implementation evaluation could comprehensively investigate, detect and monitor the implementation process and results of the planning, and on this basis, form a feedback system of relevant information, to propose advices to adjust and correct the content, policy design, and the mechanism framework of plan, and make the operation of the planning process into a virtuous cycle. Therefore, as an important and integral part, the evaluation research of planning implementation throughout the entire process in the operation system of land use planning in modern times.

Since the 21th Century, research of the implementation evaluation on land use planning in China has made significant progress, and China worked out related laws and regulations to adjust land use at a macro level, made sure the basic content and intended target of implementation evaluation, proposed to establish a guarantee system of dynamic monitoring, evaluation and management of the implementation. Chinese scholars had achieved great progress in the study of indicator system and weight and evaluation method of the implementation evaluation on land use planning. Compared with the foreign, the implementation evaluation on land use planning in China started late, related theories not be sufficiently mature and need to prefect the system construction and innovate the research method, and the implementation and effect should also be concerned in the implementation of related planning. Based on the existing case study, find a large number of domestic and foreign literature, finishing to the existing land use planning implementation evaluation summary, lack of analysis, and a series of evaluation method on the induction, explores the problems in its future development and direction of development. 


\section{THE RESEARCH OF IMPLEMENTATION EVALUATION ON LAND USE PLANNING AT HOME AND ABROAD}

\section{A. The Research of Implementation Evaluation on Land Use Planning in China}

The integrated land use planning is make a general arrangement on the land use in the administrative region at all levels, which in a quite long time (usually is 15 years) according to characteristics of land resources and the need of social and economic development. The integrated land use planning in China It experienced three stages:

- The first round of integrated land use planning carried out in the conditions of the land administration law enacted in the 1980s. The main character is decompose and practice the macro-control of land resources level by level in the form of count through administrative systems, laid a foundation of five-level compiling system of nation, province, city(prefecture), county(district), and township. The key of the planning is properly solving the contradictions of supply and demand between cultivated land and construction land on the premise of protecting the cultivated land. While in the terms of actual preparation, the effect is not really prefect. Cai Yumei[1](2005) analyzed the first round of land use planning in China since the reform and open-up, although based on the law on land management, there is no specific stipulation that which land use planning should be reference in land examination and approval and lead to the planning has not been implemented as required. Wang Yubo[2](2011) put forward that the government is the only subject of the first round in the process of planning formulation, lack of participation of social and public-sector organizations, which lead to the planning has strong features of planned economy. At the same time, as a new thing, the social status and the legal restraint in the market economy of the integrated land use planning has not reach the height as it should be.

- The second round of integrated land use planning carried out in 1990s, reinforced the theme of the protection of cultivated land, built up the planning control system of indicators and regionalization, took a top-down layers of control of land use, and placed more emphasis on rigid control. As to the rigidity of planning, Chen Min[3](2005) proposed the planning indicator should set controlled indicators and guided indicators. The controlled indicators could not change, the guided indicators are without coerciveness. Chen Yinrong and Mei Yun[4](2005) considered that planning control indexes of layers of control by the mandatory indicators under the rigid planned to rigid target necessary to increase guidance index, such as the indicator of human settlements, ecological indicator, and so on.

- Because of the invalidation of the second round of integrated land use planning, the Ministry of Land and Resources draw up the third round of integrated land use planning in 2004. Except to improve the informational level of the planning and the technical standard, the third round of integrated land use planning expect to breakthrough conventional land use pattern, studied and explored several important problems abut land use. Took the Zhejiang province as the studied area, Zhao Zheyuan et al[5](2003) advocated adjust the compilation method of the new integrated land use planning from a macroscopic view in the way of targeted approach. In other words, planning at the provincial level, and to bipolar (Central, primary) merge, break down planning targets, decomposition indicator is based primarily on economic indicators such as city and County fiscal and taxation.

The current problems of integrated land use planning in China is short of flexibility and dynamic characteristics, beyond that, Planning focuses on establishment and implementation, the results and degree of implementation in local place after making planning need be analyzed through the evaluation of planning implementation.

\section{B. The Research of Implementation Evaluation on Land Use Planning in Foreign}

Research on theory and method of land-use planning in foreign countries started earlier, scholars' ideas on the evaluation of land-use planning formed in 1960s, and has already formed a relatively complete theory and technical support, there is also a fully research on the implementation of land use planning and related methodology is more comprehensive. Alternant(1978) and Hill[11] compared the land use planning and land use status by using the spatial averaging technique, got the conformance and non-conformance of the planning implementation, reviewed and analyzed other factors such as political of the effect of planning implementation. This research turned on the new way of analyzing and evaluating the results of planning implementation quantitatively. Another is the supervision system of planning which put forward by Calkins[12](1979), this system consists of two parts: a series of rational planning process and information system of planning support.

This indicator system can provide lots of information for amending plan, and it can also be used to evaluate the effectiveness of planning as a means of development control, this approach is limited to introducing the theory, does not provide actual results and indicator system which can be used for reference. As early as 1989, foreign scholars proposed to evaluate the process and results of planning implementation, there is no necessary to request the implementation results completely in conformity with the planning scheme at the time of evaluating the implementation results, but focus on the anastomosis of purport of implementation results and planning scheme. To this issue, Alexander[13](1989) established the PPIP evaluation model (the evaluation of Policy-Planning Implementation Process), he put forward that as long as the purport of planning programming had not changed, the implementation of land use planning is successful 
even if planning results inconsistent with the plan planning scheme.

\section{GENERALIZING OF IMPLEMENTATION EVALUATION ON LAND USE PLANNING}

The implementation evaluation on Land use planning is a kind of value judgment that according to related standards and using a certain method to analyze, compare and synthesize the implementation effect of land use planning. Feng Jianmei, Chen Longqian et al[14](2011) think that the integrated land use planning is the premise of revision, and the important measure to guarantee the implementation evaluation on Land use planning can be properly sequenced and implemented. Gao Xirui, Zhang Yongfu et al[15](2009) considered that the implementation evaluation on Land use planning could check out the implementation effect of last round of the planning and find out the problem in the implementation process, and provide scientific basis for new round of the integrated land use planning.

\section{A. The Research on Indicator System of Evaluation of Planning Implementation}

The integrated land use planning is a kind of macro-control measure that aim at the layout construction and partial allocation of land use in space-time about future according to regional natural and social conditions and the needs of economic development in a certain time and space. Because the land-use system is a complicated human-land compound system, the constitution of evaluation indicator system in implementing assessment of planning is the research priorities among the scholars at home and abroad.

Zhao Xiaomin et al[10](2003) considered that a complete system about implementation evaluation on land use planning should include aspects: valuator, evaluation object, evaluation purpose, evaluation criterion or indicator system, evaluation method. The indicator system classified into two categories, one is the effect index, mainly include social cognition, rate of input-output, rate of environmental improvement and the rate of productivity increases; the other is the perform index, the main indexes include performability index, limited index and the breach of planning conditions index. The perform index consists mainly of land development, land consolidation, land rehabilitation, returning cultivated land to forestland or lake or grassland and so on. The limited index includes the maximum index (construction land area, cultivated land occupation area, the scale of Urban expansion and so on), and the lower limit index of basic farmland protection area. The breach of planning conditions index includes incidence rate and dealing rate of breach of planning conditions, and the like.

On the basis of the Analytic Hierarchy Process, Zhou Huijie et al[16](2005) built a general evaluation system of the implementation evaluation on land use planning: the target layer(P), criterion layer(A), sub-criteria layer(B) and measure layer(C), and set up a relevant index system based their own characteristics. Zheng Xinqi et al[17](2006) learn from the relevant research results at home and abroad, based on expert argumentation time after time, came up with a three level evaluation indicator system: set 5 first grade indexes, 30 second grade indexes, 12 third grade indexes. Yu Xiangke[18](2006) set up index system which include three classes. The first one is the indicator system of objective evaluation, consisted of cultivated land quantity, grain for green area, the indicator of newly increased construction land area and adjustment of land use structure. The second one is the indicator system of benefit evaluation and evaluate the economic benefit, social benefit and the ecological benefit. The third one is the indicator system of influence evaluation, main analysis the effect of economic, ecologic and social system in the implementation process of land use planning.

Xia Chunyun and Yan Jinming[19] (2006) proposed the principle of setting up the indicator system of the implementation evaluation on land use planning, systematically designed the frame of indicator system of the implementation evaluation on land use planning, the policy, the land use improvement level, the implementation effect of planning scheme and the social influence, and the benefit of economic, social and ecological. Lv Changhe et al[20](2007) designed 11 indicator that used to forecast and assess the likely effects scale of land use planning on environment, ecology and land resources from 5 aspects, the environmental protection, land degradation control, protection of cultivated land resources, moderation and aftereffects of construction land growth and cultivated land requisition-compensation balance.

He Meili[21](2008) put forward the indicator system of "pressure-state-response" on the basis of research of relate evaluation system. According to the ideas of result analysis, process supervision, influence assessment and reason analysis, Du Jinfeng[22](2008) divided the implementation evaluation on land use planning into 4 aspects, the evaluation of realization extent of planning objective, the evaluation of implementation and measure of planning, the evaluation of planning implement effect and the summary and suggestion of planning implementation issues. On this basis, designed a four-level evaluation indicator system that includes destination level, the main factors level, the derived factors level, and the factor level. The system specifically include: the evaluation of land data attributes indicator, the evaluation of land spatial layout review, the evaluation of planning implement of policies supporting, the evaluation of planning policies implement, the evaluation of benefits of planning implement, the evaluation of degrees of planning approval and abide. The research above provide a number of useful ideas and basis for building indicator system of implementation evaluation on land use planning.

\section{B. The Research on Weight of Evaluation of Planning Implementation}

Determination method of the weights of the assessment indicator system: according to different sources of raw data, the determination method classified into two categories, the subjective weight method and the objective weight method. The subjective weight method obtained by specialist through the subjective judgment which based on the experience, such as the Delphi method, the Analytic Hierarchy Process(AHP), the 
Critical Success Factors(CSF), the Fish Bone Diagram(FBD), the arithmetic method, the regression coefficient method, the Fuzzy Comprehensive Assessment Method and the Grey Relational Analysis Method, and so on.

For the most part, these methods through the collecting and collating the data related to land use planning, establishing the synthetic evaluation model and the indicator system of the implementation evaluation on land use model, and then evaluating the implementing benefit of land use planning in recent years. The raw data of the objective weight method formed in real data of the evaluation indexes in evaluated unit, and be independent of the subjective judgment. Such as the method of fuzzy weights evidence, the neural network method, and so on. These methods based on data-driven mechanisms of adaptive systems, for instance, the neural network method, which has a cumbersome reasoning process and complicated algorithm, and cannot make efficient use of the existing knowledge and experience that often results in the extracted rules gets more difficult to explain. There are three most common methods in China at present to determine index weights of the implementation evaluation on land use planning: the Delphi method, the Principal Component Analysis (PCA), and the Analytic Hierarchy Process.

Xia Jianguo[23] (2000) divided the indicators of cultivated land in North Shaanxi Province through the Principal Component Analysis, made a tentative study on quality evaluation of cultivated land. Xu Qingfu[24](2004) established the synthetic evaluation model and the indicator system of the integrated land use planning through the Delphi method. Zhou Huijie[16](2005) made a quantization study on implementation effect of the integrated land use planning in Guigang in Guangxi province through the Interval Analytic Hierarchy Process. Tian Shuai and Liu Xiuhua[25](2006) applied the Square Root Method weighty analysis about every evaluation indexes of land use, and then estimated the benefit of the planning evaluation. In the evaluation of Jingshan county, Zhang Xuesong[26](2008) determined the weight of assessment index through the Analytic Hierarchy Process. Take the Youxian district in Mianyang in Sichuan Province as study area, Li Zhangcheng[27] (2011) evaluated the implementation effect of the last round of integrated land use planning by the Analytic Hierarchy Process. Based on the Principal Component Analysis and the coordinate developmental models, Wang Feng and Ye Changsheng[28](2011) used the statistical data between 1995-2007 in Guangzhou made an empirical analysis in condition of coordinated development between land use and ecological environment. Jin Gui[29](2014) studied the cultivated land resource in the Yarlung Zangbo river and its two tributaries in Tibet, sifted evaluation factor and determined the weight by the method of fuzzy weights evidence. To some extent, this overcome the strong subjective and the defects that the deficiency in driven approach of factor selection and weight definition about the knowledge driven method.

\section{The Research on Method of Evaluation of Planning Implementation}

The focus of the current study is the method of the implementation evaluation on land use planning, the most common methods include the Paired comparison Method, the Analytic Hierarchy Process, the integrated evaluation method, the fuzzy comprehensive evaluation method, and so on, and each method has its own preponderances and shortcomings.

He Xiaochun, et al[30](1992) took the tabulated solution into the chain substitution approach, to evaluated the degree of influence of various factors to the research. $\mathrm{Wu} \mathrm{Xiu}[31](2005)$ considered that most important character during the course of the planning is the non-determinacy and under the synthetic effect of several factors, while the fuzzy comprehensive evaluation method has an advantage in dealing with this kind of problems, therefor introduced the fuzzy comprehensive evaluation method to estimates the effect of implementation of general land use planning. Tang Jianglong and Zhao Xiaomin et al[32](2005) used the ideal point method to select the superior ones in various planning, the advantages of this method is able to reflect the nuances of planning, different from the fuzzy analytical method, make them easier to implement and understand, and the results of assessment are reliable.

Under the views of sustainable utilization, Chen Qiuli and Mao Dehua[33](2007) applied the method of ecological footprint to the implementation evaluation on land use planning, analyzed the utilization degree of humans to sources, and then reflected that whether the land use was sustainable. In considering the systematization and complicacy of the implementation evaluation on land use planning, Chen Haisu[34](2008) combined the Analytic Hierarchy Process and the fuzzy comprehensive evaluation method, built the AHP_FURRZY model, and established a targeted indicator system to evaluate the implementation of the land use planning. Zhang Xuesong and Zhang Ying et al[35](2008) introduced the utility function into the implementation evaluation on land use planning, quantified each evaluation indicator by using certain methods, and turn into a quantization value to measure the value, that is the value of utility functions, and then get the last evaluation value by weighting synthesized through synthetic model.

Xu Chuntao[36](2010) applied the regression analysis method to the implementation evaluation on land use planning for the first time, not only analyzed the variable tendency and variable quantity of each indicator, but also reflected the relation among the indicators. Zhu Qilian[37](2010) pointed out that the implementation evaluation on urban master planning which in the perspective of public should make full use of the Aggregative indicator method and the opinion polls method, perfected the planning implementation evaluation model which combined by from top to bottom and from bottom to top. Li Na and Hao Jikun[38](2011) adopted the factor analytic method to analyze the indicator system of economic, social benefit and ecological benefit in Hengshui in Hebei province, quantitatively reflected the economic, social benefit and ecological benefit of plan implementation every years, accordingly to improve reliability of benefit evaluation of the plan implementation. Chen Baiming et al[39](2011) came forward that use the Analytic Hierarchy Process and 
matter-element analysis method and the like to make quantum chemical calculation and dynamic comprehensive evaluation to the land use ecological security status. Wang Xinsheng and Zhang Hejun[40](2012) used ANP method to build the implementation evaluation on land use planning model, analyzed the reasonability of implementation of integrated land use planning in Jiaozuo, which better take into account the relationship of interdependence and feedback at all levels and all factors.

In recent years, due to the limitations of some methods, for instance, the analytic hierarchy process method only consider the upper-level factors that affect to the next level, single and traditional method can't meet the demand of the implementation evaluation on land use planning at the present stage. Therefore, the related scholars combined different methods to construct a new evaluation system. For example, Bai Yu[41](2012) improved the departed ecological footprint model, applied the Macro trade regulation method to ecological footprint calculation, made a more accurate calculation to land use planning in Tianjin city. Sang Jin[42](2013) concluded and summarized many different using methods and application fields about the multiple regression model, compared with foreign countries, Sang Jin made some recommendations on the application of this method in China in currently. Gao Qi[43](2013) combined the FUZZY model with the PSR model and made an evaluation on integrated land use planning in Houma city, combined the three levels of land use study about PSR model with the fuzzy uncertainty of FUZZY model, provided new ideas for the implementation evaluation on land use planning in China.

Above the commonly research methods, the ideal point method be used to select the planning scheme before the planning implement. The sustainable degree model and the method of ecological footprint is the means to make global evaluation to the implementation to the planning, the evaluation of specific indicators of land use control is not enough, and the method of ecological footprint needs a lot data. The Analytic Hierarchy Process, the fuzzy comprehensive evaluation method, the AHP-FUZZY model, the PRS model, the method of the utility function, the grey integrative evaluation method and the regression analysis method used to evaluate the evaluation indicators of structure and layout of land use and the land use control.

The Analytic Hierarchy Process comparatively simple in these methods, but due to significant difference of several indicators, the implementing assessment of planning may be significant differences may be seriously impacted. The fuzzy comprehensive evaluation method avoided above shortcoming, but the precision is not enough. The AHP-FUZZY model compromised the merits of the Analytic Hierarchy Process and the fuzzy comprehensive evaluation method, while the counting process is complicated.

The PRS model mainly used for building a systematic indicator system from the perspective of "stress- statusresponse". The method of the utility function is simple in calculation, and the key of this method is the selection of the synthetic model. The others methods have their own advantages and disadvantages, for this reason, the endeavor to explore other methods should be strengthened.

\section{The Research on Case and Hotspot of Evaluation of Planning Implementation}

- Land use planning is actually a continuous development

of

"plan-implementation-evaluation-re-planning-re-i mplementation", through the continuous feedback of evaluation of planning implementation to reflect the scientific of planning, and the dynamic evaluation of planning implementation provides new ways for the evaluation of land use planning. In recent years, some scholars discussed the dynamic evaluation of land use planning implementation. Li Dengqin[44](2010) proposed the idea of annual evaluation of planning implementation, by studying the implementation effect of integrated land use planning and the problem in implementation process in Guizhou province, found that the implementation effect of integrated land use planning has obvious fluctuations, and policy continuity of planning implementation is not strong, so it is imperative about the immediate evaluation and dynamic adjustment in implementation, and the research think that the dynamic evaluation benefits the immediate evaluation and long-term management of integrated land use planning. Wang Wanjing[45](2013) defined the concept and connotation of implementation evaluation on land use planning based on the space anastomotic, and constructed the spatial alignment measurement model which is oriented the implementation process and results from 3 levels, that is class diagram spot, functional area and region, and made the corresponding classification standard of spatial alignment. According to the analysis of theories at home and abroad and combined practical land use of Doilungdêqên County in Lhasa city Dong Guanglong[46](2013) set up a primary basic theory framework evaluation system of the implementation evaluation on land use planning suitable for China: 1) the evaluation based on spatial anastomotic; 2) the evaluation based on utility function method. Zhong Guohui[47](2015)argued that the key of dynamic evaluation of land use planning is to calculate the maximum of newly-increasing construction land can sustain during the planning period. Take the Jincheng city in Shanxi province as study area, based on the evaluation indicator system of regional natural environment quality which is built by the subsystems include water environment, soil environment, atmospheric environment and ecological environment, Liu Chang et al[48](2015) made dynamic assessment by using both entropy weight method and Matter-Element model to analyze the time cumulative effect and distribution regulation of the effect on regional environment caused by the implementation of land use planning.

- The static evaluation is corresponds to the 
dynamic evaluation of land use planning implementation, the research on static evaluation has an earlier start and relative mature than dynamic evaluation. Yu Xiangke[18](2006) made horizontal and vertical comparison for planning implementation benefits in Shizhong district of Suining city, but only divided economic class in County City State when choose the comparison area, there is no choice to compared with the same level of regional to compares and analyses, so there are still some deficiencies. Sun Zhibo[49](2007) taken the fuzzy comprehensive evaluation method to evaluate the effect of planning implementation and made longitudinal comparative and analysis on the results of evaluation of planning implementation. Liu Liu[50](2007) took the fuzzy comprehensive evaluation method to evaluate the planning implementation in Leshan city, and pointed out that should increase the horizontal comparative evaluation on planning implementation in regional both inside and outside when summarizing insufficient. Long Ying[51](2011) believed that the most of the studies at present are compare the consistency between the results of planning implementation and development situation in a certain time and space, these belong to the static space time evaluation method aim at the results of planning implementation, and pointed out an time and space dynamic evaluation method of planning implementation based on Logistic regression and GIS. Divided 1947 to 2008 into 5 stages and analyzed the drive factor of city extended in every stage, recognized the promotion of city expansion of different version in different stage. In addition, took 2004-2008 as study period and each district(country) as study area, suburb and outer suburban district, recognized the spatial heterogeneity of integrated planning in city expansion.

- The Eighteenth National Congress of CPC proposed the national spatial development pattern of intensive and high efficiency in production space, livable and suitable in living space, picturesque in ecological space, built up PLF spatial classification system that based on production, life and ecology, which became the important prerequisite of making territory development plan and optimizing the spatial pattern. Therefore, the study on evaluation on PLF benefits is the hot subjects in the implementation evaluation on land use planning, there ecological effect evaluation case of the land planning implement as follows: Bian Zhengfu ea al[52](2004) divided the Land Use Planning Environment Impact Assessment(LUPEIA) into three levels: the Land Use Overall Planning Environment Impact Assessment(LUOPEIA), the Land Use Specialized Planning Environment Impact Assessment(LUSPEIA), and the Land Use Project Planning Environment Impact Assessment(LUOPEIA). In addition, preliminarily established the LUPEIA system in
China and proposed the effect of LUPEIA based on the PSR frame, relevant documents of FAO and EIA program, classified the sustainability of land use assessment into the main content of LUPEIA. Since then, many scholars have researched the relevant theory and method of the implementation evaluation on land use planning. Tang Yan and Huang XianJin et al[53](2005) analyzed the content of the ecology benefits assessment of land use planning implementation, considered that the main content of the ecology benefits assessment implementation is the influence degree of the environmental factor such like water resources, plants, soil, air, animals, landscapes, and the ecology process after the land use planning implementation. Based on the foundation of the review of the research progress on the evaluation of ecosystem service function value, Tang Tao et al[54](2007) analyzed the necessity of ecosystem service function value assessment in the implementation evaluation on land use planning, comprehensive assessment of the ecological benefits of land use planning objectives and planning programs is simple, it is benefit for EIA to save time and resource. Chen Yongsheng and Ju Minrui et al[55](2011) proposed that land resource is the important basis of the development of human and society survival and the irreplaceable means of production of agriculture, it has a direct impact on the benefits of agriculture production and concerning the sustainability of agriculture and society. Coupled with the chart of ecology service value amended by Xie Gaodi, Sun Liwei et al[56](2013) analyzed the ecological benefits of land use / cover change in the middle and lower reaches of Shule River with Constanza in the perspective of ecosystem service function. Chen $\mathrm{Yu}$ et al[57](2015) constructed a geographical weighted regression model with GWR, analyzed the spatial differentiation characteristics of the driving factors of the land ecology service value and provided a reference to the coordinated development of regional ecological economy.

\section{CONCLUSION AND FUTURE OF IMPLEMENTATION EVALUATION ON LAND USE PLANNING UNDER THE EXTENSION VIEW}

The research of implementation evaluation on land use planning in our country has gone through more than 10 years and made great progress, there are still problems in the field of research because the implementation of the evaluation work started late, mainly in the following aspects: (1)National macro-control and implementation of the intensity of land use is not enough, while the scientific nature in the process of implementation is relatively low, and the condition of planning implements need to improve. The current "land management law" lack of legal basis of land use planning implementation evaluation and normalization. (2) The implementation evaluation on land use planning in currently is short of fundamental research. (3) The indicator system of implementation evaluation on land use planning needs to 
be improved, the scientific basis is insufficiency in the link of selecting the evaluation indicators and threshold, especially in the process of explaining the results of multi-index integrated evaluation method, the subjective intention was too strong. (4)The study of the evaluation of planning implementation exists a tendency of one-sided pursuit the quantify and do not attach importance to the establishment of evaluation criteria. In addition, the main body of the current implementation evaluation on land use planning is the local land administrative depart and the units commissioned by the planning unit. This organization mode greatly reduces the scientific nature of the planning implementation evaluation and have an impact on the quality of the evaluation results.

Aimed to the disadvantages listed above and the prediction of the trend of implementation evaluation on land use planning in the future, the implementation evaluation on land use planning will face the following topics:

(1) There is necessary to establish an operability theory of implementation evaluation on land use planning according to the actual situation of land use in China based on the research status of lacking in theoretical basis of implementation evaluation on land use planning in currently, improve the mechanism of implementation evaluation on land use planning. Although scholars have carried out a lot of research on the methods of implementation evaluation on land use planning, due to the complexity of implementation evaluation system, the current method could not meet the needs of the implementation evaluation on land use planning, the study on evaluation method of systematic and dynamic should be further strengthen.

(2) Based on the establishment of "production, life and ecology" spatial classification criteria proposed on the Eighteenth National Congress of CPC. Therefore, it is necessary to expand the concept and the method of the land use classification, increase the consideration of the property of land quality and land use profit, increase the evaluation research on PLF benefits of the implementation on land use planning. At present, there are many researches on the evaluation of ecological benefits of land use planning in China, but there are few examples of research on production efficiency and benefit evaluation. Therefore, it is necessary to increase the research on the profit of production and life of the future evaluation of land use planning implementation, and let the work of the evaluation of land use planning implementation closely adhere to national policy, not only evaluating the result of the last round land use planning implementation while provides compilation basis to the next round, but also keep pace on the times at the macro level.

(3) Land resource is a comprehensive functional whole about nature and economy, which has function of life, production and ecology, and this corresponds to the generalized landscape concept, they are not only the result of the nature evolution, but also the result of human activity. With the development of society and economy, the land management has gradually formed the way of land use, generated the category of land use combined with land use units. However, the mosaic of different land use category generates land use landscape. The macroscopic and integral characteristics of landscape ecology provide a new way of thinking for land use planning, in the future, the study on the landscape spatial pattern and land use optimization layout can deepened in the evaluation of land use planning. The evaluation method of landscape spatial pattern can provide a tool for the evaluation of land use environment, and establish the environmental impact assessment system of land use planning based on landscape ecology.

\section{REFERENCE}

[1] CAI Yumei, XIE Jun-qi. Evaluation of land use planning in China since the reform and opening up [J]. Resources investigation and evaluation, 2005, 22:57-61.

[2] WANG Yubo. Research on the game governance of the central and local government land use overall planning [J]. Journal of Nanjing Agricultural University (Social Sciences Edition), 2011, 11(4):73-79.

[3] CHEN Min. Study on the "rigidity" and "flexibility" in the overall planning of land use at county level [D]. Southwestern Normal University, 2005.

[4] CHEN Yinrong, MEI Yun. Thoughts on the coordination of land use planning and urban planning in the process of Urbanization [J]. China Population Resources and Environment, 2006, 16(1):30-34.

[5] ZHAO Zheyuan, HUA Yuanchun, WU Cifang. Investigation of a new round overall planning of land use [J]. Management Geological Science and Technology, 2003, 20(5):9-15.

[6] GONG Hua, LI Guicai. Research on transforming land use planning under China's Rapid urbanization: A case study of Shenzhen. [J]. Urban Development Studies, 2015, 22(12):25-30.

[7] SHI Jingwen. Discussion on the benefit of land use planning [J]. Hubei Agricultural Sciences, 1992(11):36-37.

[8] SHI Xueyi, WANG Yunping. The appraisal and choice of the overall plan for land use [J].Journal of Shanxi Agricultural University, 1994(01):30-32.

[9] SUN Shiwen, ZHOU Yu. Theory and method of evaluation of urban planning implementation [J].Urban Planning Forum, 2003(2):15-20, 27.

[10] ZHAO Xiaomin, GUO Xi. Evaluation on the implementation of the overall land use planning [J].China Land Science, 2003, 17(5):36-41.

[11] R A, M. H. Implementation of urban land use plans [J]. AIP Journal, 1978:274-285.

[12] W. C H. The planning monitor: an accountability theory of plan evaluation [J]. Environment and planning A, 1979, 7(11):745-758.

[13] Alexander E R, Faludi A. Planning and Plan Implementation: Notes on evalution criteria Environment and Planning [J]. Planning and Design, 198(16).

[14] FENG Jianmei, CHEN Longqian et al. Evaluation on the Implementation of the Overall Planning of the overall planning of land use in Zhongmu County [J].Anhui Agricultural Science Bullentin, 2011,17(13):9-10, 48.

[15] GAO Xirui, ZHANG Yongfu et al. Evaluation of general plan of land use in Akesu City,Xinjiang [J].Xinjiang Agricultural Sciences, 2009,46(1).

[16] ZHOU Huijie, ZHOU Xin et al. The evaluation of implementation of general land use planning in Guangxi Guigang City [J]. Ecological Environment, 2005(05):752-756.

[17] ZHENG Xinqi, LI Ling et al. Evaluation types and method of land use planning [J]. China Land Science, 2006, 20(1):21-26.

[18] YU Xiangke, DENG Liangji et al. A Discussion on evaluation method of Implementation of Land Use Planning [J].Scientific and Technological Management of Land and Resources, 2006, 23(1):32-36.

[19] XIA Chunyun, YAN Jingming. Construction of evaluation index system of land use planning [J].China Land Science, 2006, 20(2):19-23.

[20] LU Changhe, JIA Ke jing et al. Indicators for assessing the 
ecological and environmental effects of integrated land use planning and their application to a case study [J]. Geographical Research, 2007, 26(2):249-257.

[21] HE Meili, ZHOU Yong. Current situation of research on evaluation of land use planning in China [J]. Scientific and Technological Management of Land and Resourrces, 2008, 25(2):41-44.

[22] DU Jingfeng, FENG Changchun. Research on the main problems of the current evaluation of the overall land use planning in China [J]. China Land Science. 2008(10):74-80.

[23] XIA Jianguo, LI Tinxuan et al. Application of principal component analysis in the evaluation of cultivated land quality [J]. Southwest China Journal of Agricultural Sciences, 2000(02):51-55.

[24] XU Qingfu, BI Cuihong et al. Application of Delphi method in making total plan of land using[J].Land and Resources in Shandong Province, 2004,20(6):36-39.

[25] TIAN Shuai, LIU Xiuhua. Application of a quantitative model in dynamic evaluation of land use planning [J]. Journal of Southwest Agricultural University (Social Science Edition), 2006, 4(4):8-11.

[26] ZHANG Xuesong, ZHANG Ying, ZHAI Zhenhua. Evaluation of land use planning based on utility function comprehensive evaluation method-a case study of Jingshan County [J]. Journal of Huazhong Normal University (Natural Sciences), 2008, 42(4):631-635

[27] LI Zhangcheng, YANG Juan, REN Guoye. The evaluation of implementation of overall land use planning in Youxian District of Mianyang city as an example [J]. Southwest China Journal of Agricultural Sciences, 2011, 24(3):1013-1016.

[28] WANG Feng, YE Changsheng. Study on the coordinated development of land use and ecological environment in Guangzhou City [J]. Research of Soil and Water Conservation, 2011, 18(3):238-242, 246.

[29] JIN Gui, WANG Zhanqi et al. Suitable evaluation on cultivated land based on fuzzy weights of evidence method in the Yarlung Zangbo River,Nyangqu River and Lhasa River region,Tibet[J]. Journal of natural resources, 2014(07):1246-1256.

[30] HE Xiaochun, LI Changlin, TONG Xinyu. The application of serial substitution method in the evaluation of planning implementation [J]. System Sciences and Comprehensive Studies in Agriculture, 1992(04):279-281.

[31] WU Xiu. Evaluation method of land use planning based on fuzzy comprehensive evaluation [D]. Wu Han: WuHan University, 2005.

[32] TANG Jianglong, ZHAO Xiaomin, SHI Xueyi. Application of ideal point method in the evaluation of land use planning [J]. Transactions of the Chinese Society of Agricultural Engineering, 2005, 21(2)

[33] CHEN Qiulig, MAO Dehua. Application of ecological footprint in the evaluation of implementation of general land use planning [J]. Resources Environment and Engineering, 2007, 21(3):348-351.

[34] CHEN Haisu, WU Shidai. Analysis of dynamic change of Land use and its driving forces in Fuqing[J]. Journal of Ningxia University (Natural Science Edition), 2008, 29(1):91-96.

[35] ZHANG Xuesong, ZHANG Ying, ZHAI Zhenhua. Evaluation of land use planning based on utility function comprehensive evaluation method-a case study of Jingshan County [J]. Journal of Huazhong Normal University (Natural Sciences), 2008, 42(4):631-635.

[36] XU Chuntao, JIANG Xidong. Regression analysis in land use planning evaluation-case study on Yitong County in Jilin Province [J]. Journal of Northeast Normal University (Natural Science Edition), 2010, 42(4):154-158

[37] ZHU Qilian. Research on implementation evaluation of city master plan in a public-policy-based perspective: A case of Beijing City master plan (2004-2020) [D]. Renmin University of China, 2010.

[38] LI Na, HAO Jikun. Evaluation on the implementation effect of general plan for land use of Hengshui City based on factor analysis [J]. Journal of Anhui Agricultural Sciences, 2011, 39(13):7872-7874.

[39] CHEN Baiming, ZHANG Fengrong. Trend and priority areas in land use research of China [J].Geographical Research, 2011,
30(1):1-9.

[40] WANG Xinsheng, ZHANG Hebin. Evaluation of land use planning implementation based on ANP method: a case study of Jiaozuo City [J]. Chinese Journal of Agricultural Resources and Regional Planning, 2012, 33(6):62-66, 100.

[41] BAI Yu. Assessment of Eco-efficiency of Tianjin land use master plan based on ecological footprint model [J]. Economic Geography, 2012(10):127-132.

[42] SANG Jin. A positive study on multivariable regression model based planning implementation evaluation [J]. Planners, 2013, 29(10):79-85.

[43] GAO Qi, SHI Xueyi et al. A study on evaluation of general land use planning implementation based on the model of PSR-FUZZY [J]. Acta Agriculturae Universitatis Jiangxiensis, 2013, 35(2):427-432.

[44] LI Dengqin. Implementation dynamic evaluation of land utilization overall plan in Guizhou [J]. Guizhou Agricultural Sciences, 2010(08):236-238.

[45] WANG Wanjing, CHUAI Xiaowei et al. Method of implementation evaluation on general land use planning and its application based on spatial concordance [J]. Transactions of the Chinese Society of Agricultural Engineering, 2013, 29(4):1-14.

[46] DONG Guanglong. Dynamic assessment on the implementation of general land use planning [D]. China University of Geosciences (Beijing), 2013

[47] ZHONG Guohui. Dynamic evaluation of land use planning in big cities [J]. China Collective Economy, 2015(25):1-2.

[48] LIU Chang, SHI Xueyi, GAO Qi. Environmental impact dynamic tracking assessment of land use planning based on entropy weigh and matter element model [J]. Acta Scientiae Circumstantiae, 2015(08):2641-2647.

[49] SUN Zhibo, XU Yueming. Index system on urban land intensive utilization [J]. Journal of Anhui Agricultural Sciences, 2006, 34(22):6020-6021.

[50] LIU Liu, HUANG Yun, GAO Deshan, Study on environmental impact assessment of land use planning-taking Ebian County in Leshan city as an example [J]. Journal of Anhui Agricultural Sciences, 2007, 35(8):2348-2349.

[51] LONG Ying, HAN Haoying et al. Spatio-temporal evaluation of urban planning implementation [J]. Progress In Geography, 2011(8):967-977.

[52] BIAN Zhengfu, LU Yunge. Environmental impact assessment in land use planning [J]. China Land Science, 2004, 18(2):21-28.

[53] TANG Yan, HUANG Xianjin. Study on eco-environmental benefit of implementation in general land use planning [J]. Ecological Planning, 2005(10):229-232.

[54] TANG Tao, ZHU Tan et al. Application of ecosystem services evaluation in environmental impact assessment on land-use master planning [J]. China Population, Resources and Environment, 2007, 17(3):45-49.

[55] CHEN Shengyong, JU Minrui. Research progress on comprehensive evaluation of land resources [J]. Technology of Soil and Water Conservation, 2011(05):25-28.

[56] SUN Liwei, ZHANG Bo et al. Ecological benefit of land use/cover change in endorheic drainage-A case study on the middle and lower reacher of Shule River [J]. Journal of Arid Land Resources and Environment, 2013, 27(3):80-85.

[57] CHEN Yu, LI Jiangfeng, XU Jia. The impact of socio-economic factors on ecological service value in Hubei Province: A geographically weighted regression approach $[\mathrm{J}]$. China Land Sciences, 2015(06):89-96. 